\title{
Breaches of the main categories of life activities among disabled people of working age, caused by cerebral stroke
}

Volume 6 Issue 4 - 2017

\section{Opinion}

It is necessary to evaluate not only dysfunctions of ill and disabled people after cerebral stroke, but for successful rehabilitation breaches of the main functions of life activities as well and the possibilities of their lessening. In the course of medical and social examination in accordance with current legislation one should evaluate seven main categories of life activities: ability to self-service, ability to move selfreliantly, ability to orientation, ability to communication, ability to self-control of behavior, ability to education and ability to work. We studied the structure of limitations of 2000 disabled people of working age, initially considered invalids after cerebral stroke.

During the study of the limitations of life activities after the cerebral stroke we determined that all people, who were acknowledged disabled, had different degrees of limitations, it was observed during the whole period of study from 2010-2015. All disabled people had troubles in performing their professional activity and could not fulfill the same volume, quality, content of work as before, in the same working conditions. Second significant limitation after cerebral stroke - is limitation of self-service ability. During the period of study we determined that $88,5 \%$ of disabled people had limitation in selfservice ability. In dynamics we registered the decrease in number of disabled people, having self-service limitations. Thus in 2010 this index was $91,5 \%$, and then decreased to $86,0 \%$ by 2015 . However, in 2015 this index increased again to $88,5 \%$. The share of disabled people, who had limitations in ability to move self-reliantly, have body balance when moving, at rest and changing body position, limitations in using public transport, is less than the previous index, but is still rather large $-81,0 \%$. In dynamics there is no tendency of increase or decrease, but its rate is high - $14 \%$. The maximum index was registered in $2011-84 \%$, the minimum index in 2012 and $2015-81 \%$. Limitation in ability to comprehension, remembering, understanding and reproducing information, learning the skills was registered among $50 \%$ of disabled people. The least index was registered in 2010, when we determined that $49 \%$ of disabled people have troubles in learning, the largest index in $2011-37 \%$. After 2011 the share of disabled people, having limitations in learning decreased to $47 \%$ in 2015 . $47 \%$ of studied people had problems contacting people by means of comprehension, processing and transferring information. The least index was registered in 2010, when the limitation of communication was determined among $45 \%$ of disabled people. In 2011 this index

\author{
Valeriya Tarantseva \\ Chief Bureau for Medical and Social Expertise of Rostov region, \\ Russia
}

Correspondence: Valeriya Tarantseva, Head of the expert committee, Neurologist, Chief Bureau for Medical and Social Expertise of Rostov region, Russia, Email dr.tarantseva@mail.ru

Received: September 06, 2016 | Published: April 17, 2017

grew on $11 \%$, and since 2012 it started decreasing, and reached the point of $46 \%$ in 2015 . The share of disabled people, having limitations in learning and communication, is close in meaning and dynamics to the period $2010-2015$ and has the same trend line. $29,5 \%$ of people after stroke had problems with self-control. In dynamics the index was close in 2010, 2011 and 2013, and in 2012 and 2015 increased correspondently. The least number of disabled people after stroke (23, $5 \%$ ) were limited in ability to orientate themselves in space, time and own personality. We registered undulating changes of this index with maximum in $2012-27,0 \%$ and minimum in $2015-25 \%$.

Thus, a great variety of consequences of cerebral stroke among people of working age acknowledged disabled for the first time and having dysfunctions, form limitations in all categories of life activities. The leading limitations in this category of disabled people are limitation in working activity - $100 \%$, limitation of self-service ability $-88,5 \%$, limitation to move self-reliantly $-81 \%$. It is necessary to take into consideration these indices when planning rehabilitation measures.

\section{Acknowledgments}

None.

\section{Conflicts of interest}

None.

Funding

None. 